\title{
Editorial
}

\section{An Acknowledgement to the HCA Healthcare Journal of Medicine's Reviewers and Editors for the 1st Half of 2021}

Bruce Deighton, PhD, ${ }^{1}$ Hossein Akhondi, MD, FACP,1,2 D. Scott Lind, MD, ${ }^{1,3}$ Graig Donini ${ }^{1}$

\section{Abstract}

Author affiliations are listed
at the end of this article.
Correspondence to:
Graig Donini
HCA Healthcare Graduate
Medical Education
2000 Health Park Drive
Brentwood, TN 37027
(Graig.Donini@
HCAhealthcare.com)

\section{Description}

As we reach the midway point of 2021, the HCA Healthcare Journal of Medicine would like to thank those behind the scenes that make this publication possible. Our journal would not have been possible without the assistance of our reviewers, authors and board members.

\section{Keywords}

scholarly communication; peer review, research; open access publishing; education, medical, graduate; medical journalism

The HCA Healthcare Journal of Medicine once again thanks the reviewers and editorial staff that have helped over the first half of 2021. As the medical community slowly tries to establish a new norm, continuing to write and publish results of importance to our colleagues will help us to overcome the pandemic and to effectively protect and serve our patients.

As we pass the midway point of 2021 and look forward to continued recovery, we want to highlight our next special issue of the journal. Please see our call for papers on "Health Equity in Medicine". We seek novel submissions that address health equity at every level of medicine including, but not limited to, direct patient care, physician training and systemic/structural issues. This issue will also consider other types of prose, from education and wellness initiatives to narrative essays and poetry. Artwork that relates to the topics of the special issue are also encouraged.

As always, we encourage our readers to consider submitting their own work, both scientific and personal, and ask them to consider volunteering to share their expertise as peer reviewers. Authorship and peer review with the jour- nal are forms of scholarly activity recognized by the ACGME. Email us for more information.

Thank you for your continued support of the HCA Healthcare Journal of Medicine.

\section{Reviewers}

Ahmad Abazid

Jack Abramson

Brent Acker

Aftab Ahmad

Hossein Alex Akhondi

Afsaneh Alavi

Zuhair Ali

Michael P. Allswede

Jeffrey Anderson

Kavitha Arabindoo

Jaymie Avenido

Muzammil Aziz

Stuart Bagatell

Nora Bairagdar

J. David Baxter

Haryashpal Bhullar

Vedavyasa Biliyar

Laura Blackburn

Barbara Blasko

Jamie Bolden

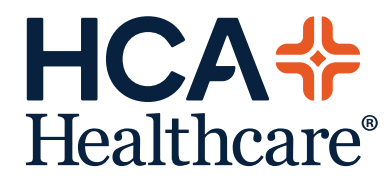

www.hcahealthcarejournal.com

(C) 2021 HCA Physician Services, Inc. d/b/a Emerald Medical Education
HCA Healthcare Journal of Medicine 
Steve Borzak

William Boyer

Ross Budziszewski

Laura Hayley Burgess

Luigi Cardella

Carley Castelein

Cristobal Cintron

Shih-Chin Chou

Nicholas Connors

Mandelin K. Cooper

Jill Cowper

Gary Dean Cravens

Ettore Crimi

Nemer Dabage

Nicholas D'Angelo

Diane Davey

Delva Deaunalimayo

William B. DeHart

James Dennis

Charles Duckworth

Oliwier Dziadkowiec

Julia Fashner

Monicka S. Felix

Mike Flynn

Shelley L. Galvin

Mallory Gessner-Wharton

Feras Ghosheh

Barbara L. Gracious

Nickie D. Greer

Anupriya Grover

Orlando D. Gutierrez

Nilmarie Guzman

Shaikh A. Hai

Jacqueline Halladay

Jon Halling

William N. Hannah Jr.

Karen E. Harris

Kimberly Helseth

Kathryn Hernando

Lisa Holtzclaw

Afra Janarious

Marcelo Jimenez

Michael R. Johnson

Mohamad Kabach

Brent Kaplan

Rahul Kashyap

Christoph Kaufmann

Adil Khan

Ubaid Khokhar

Philip Kondylis

Alexandre Koumtchev

Jessica Kraker

Jacob Krive

Michelle D. Lall
Kimberly Law

Abraham Joseph Layon

Se Won Lee

David Scott Lind

Hilary Linderman

Miriam Zylberglait Lisigurski

Abhishek Lunagariya

Sue-Wei LuU

Francisco I. Macedo

Tracy Macintosh

Denny Mack

Mathew Marsh

Elizabeth McKeown

Diana Mora-Montero

Sherri Morgan

Jason Morris

Candace R. Murbach

Mark E. Murphy

Samuel Neuhut

Kieu Nguyen

Jonathan Nieves

Jonathan Pangia

Maulik Patel

Rajul Parikh

Alicia Perry

Anush S. Pillai

Norman Pillsbury

Jamali Rabia

Afsha Rais

Fergie Ramos

Vaibhav Rastogi

Jonas M. Rawlins

Aneta Tarasiuk Rusek

Bruce St. Amour

Jose Salvador Saldivar

Jilian R. Sansbury

Anthony Shadiack

Shala Sundaram

Salim R. Surani

Stephen Thacker

Timothy Tiu

Nancy Vander Velde

Craig Van Dien

Hema Vankayala

Carlos Vargas

Jessica C. Wells

Brian E. Wood 


\author{
Editorial Board \\ Laura Hayley Burgess \\ Steve Carpenter \\ Robert Chait \\ William DeHart \\ Mary Downing \\ Julia Fashner \\ Barbara L. Gracious \\ Jacqueline Halladay \\ Julie Jacko \\ Se Won Lee \\ Abhishek Lunagariya \\ Sherri Morgan \\ Anthony Pearson-Shaver
}

\author{
Resident and Fellow Board Members \\ Patrick Melmer \\ Carlos Vargas \\ Clinical Co-Editors \\ Hossein Akhondi \\ D. Scott Lind
}

Editor-in-Chief

Bruce Deighton

Journal Production

Production Editors

Jan Haley

Heather Fach

Mary Alice Keller

Lindsay Million

Lindsay Pate

\section{Copyediting and Proofreading}

Ashton Stahl

Chris Roe

\section{Marketing and Communications}

Amy Hand

Tyler Browning

DeAndra Mack

Mary Claire Culpepper

\section{Managing Editor}

Graig Donini

\section{Conflicts of Interest}

Dr. Lind declares compensation for licensing a simulation technology.
Drs. Deighton and Akhondi and Mr. Donini declare they have no conflicts of interest.

Dr. Deighton and Mr. Donini are employees of HCA Healthcare Graduate Medical Education, an organization affiliated with the journal's publisher.

Dr. Akhondi is an employee of West Florida Hospital, a hospital affiliated with the journal's publisher.

Dr. Lind is an employee of Orange Park Medical Center, a hospital affiliated with the journal's publisher.

This research was supported (in whole or in part) by HCA Healthcare and/or an HCA Healthcare affiliated entity. The views expressed in this publication represent those of the author(s) and do not necessarily represent the official views of HCA Healthcare or any of its affiliated entities.

\section{Author Affiliations}

1. HCA Healthcare Graduate Medical Education

2. West Florida Hospital, Pensacola, FL

3. Orange Park Medical Center, Orange Park, $\mathrm{FL}$ 